\title{
The importance of environmental education for effective environmental management
}

\author{
Sergey Yekimov ${ }^{1, *}$, Viktoriia Nianko $^{2}$, Dmytro Kulagin ${ }^{3}$, Tetyana Lunkina $^{4}$, and Serhii \\ Haponenko 5 \\ ${ }^{1}$ Publishing House "Education and Science” s.r.o., Praha 8, Olstynska, 607/1, 18100 Praha, Czech \\ Republic \\ ${ }^{2}$ Dniprovsk State Technical University, Dnipropetrovsk region, Kamianske, Ukraine \\ ${ }^{3}$ National University "Zaporizhzhya Polytechnic", Zaporizhzhya, Ukraine \\ ${ }^{4}$ Mykolayiv National Agrarian University, Mykolayiv, Ukraine \\ ${ }^{5}$ Ukraine Kamenets-Podilskyi National university of Ivan Ogienko, Kamenets-Podilskyi, Ukraine
}

\begin{abstract}
The importance of environmental management is determined by the need to manage human activities related to harming the environment. The introduction of environmental management has a positive impact on reducing the anthropogenic load on the environment. Environmental management contributes to the harmonization of the relationship between man and nature. The implementation of environmental management at the enterprise largely depends on the interest of its employees in the protection of the natural environment. The preservation of the external environment is possible only if people have a responsible attitude to this problem. The effectiveness of the functioning of the elements of environmental management at the enterprise increases if the employees have a responsible attitude to environmental problems and an understanding of the environment as a human habitat, as a biological species. The social and economic development of human society is closely related to the protection of the external environment. The existing environmental problems in the modern world require a change in the thinking of humanity.
\end{abstract}

\section{Introduction}

The problem of environmental degradation has acquired a global scale. The consumer attitude of a person to the environment leads to the deterioration of his habitat. Extraction and use of natural resources, destruction and pollution of natural landscapes, brings huge harm to the environment. Environmental pollution leads to an increase in cancer and a decrease in immunity.

According to [1], it is necessary to reach a compromise between the economic needs of a person and the possibilities of the external environment.

According to [2], it is necessary to reduce the load on nature to the level at which the natural environment is able to restore its properties.

\footnotetext{
*Corresponding author: 3701313@mail.ru
} 
According to [3], environmental management is a system through which the management of activities that have or may have a negative impact on the environment takes place.

According to [4], the main task of environmental management is to reduce the pollution of nature by products of human activity, protect the environment and ensure normal living conditions.

According to [5], the following functions of environmental management can be distinguished (Figure 1):

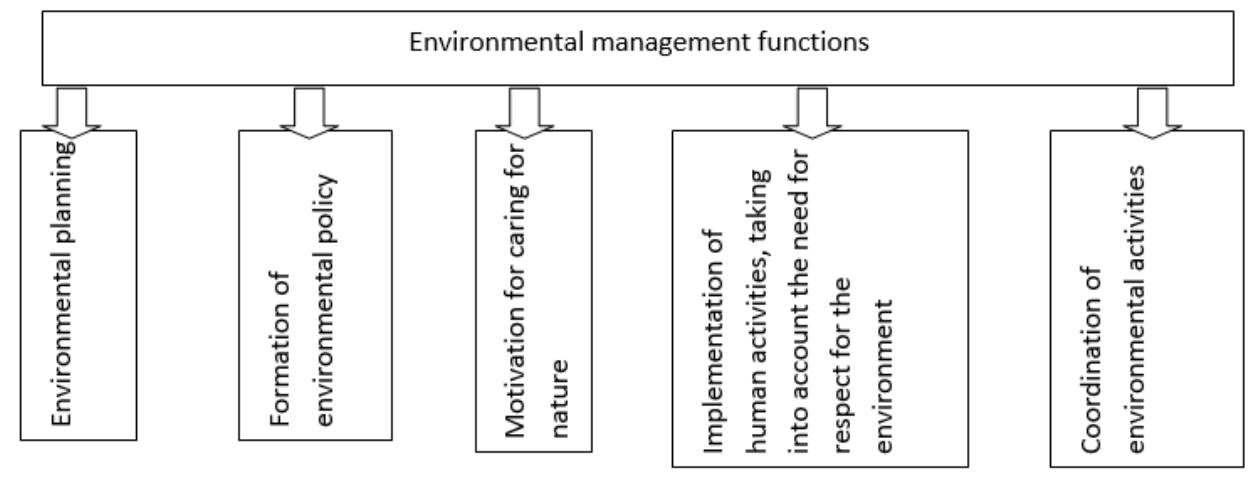

Fig. 1. Environmental management functions

According to [6], the use of an environmental management system in enterprises will allow:

1) Achieve savings in materials, raw materials, and energy resources.

2) Improve the quality of products.

3) Reduce the amount of penalties for violation of environmental legislation.

4) Attract the attention of potential investors who are interested in investing in enterprises that produce environmentally friendly products.

5) Increase the competitiveness of manufactured products.

6) Strengthen a positive image among consumers

The economic and social development of human society is closely correlated with the protection of the external environment. The existing environmental problems in the world require a change in the thinking of humanity. First of all, this applies to people's ecological culture, ecological consciousness and ecological competence.

According to [7], the process of forming ecological culture and ecological thinking should start from early childhood and continue continuously and purposefully throughout life.

According to [8], a person should have formed ecological knowledge and skills of interaction with the natural environment, in his mind it is necessary to form an ecological model of behavior.

According to [9], the goal of forming an ecological culture is to foster a careful, responsible and attentive attitude to the natural environment.

According to our opinion, this can be achieved through purposeful and systematic activities to form a complex of environmental knowledge in people. This knowledge should be oriented towards an understanding of environmental rules and regulations in relation to the environment.

According to [10], the process of forming an ecological culture can occur not only during training at an educational institution, but also outside of educational activities.

The authors [11] highlight the basic principles of environmental education and the formation of environmental culture (Figure 2): 


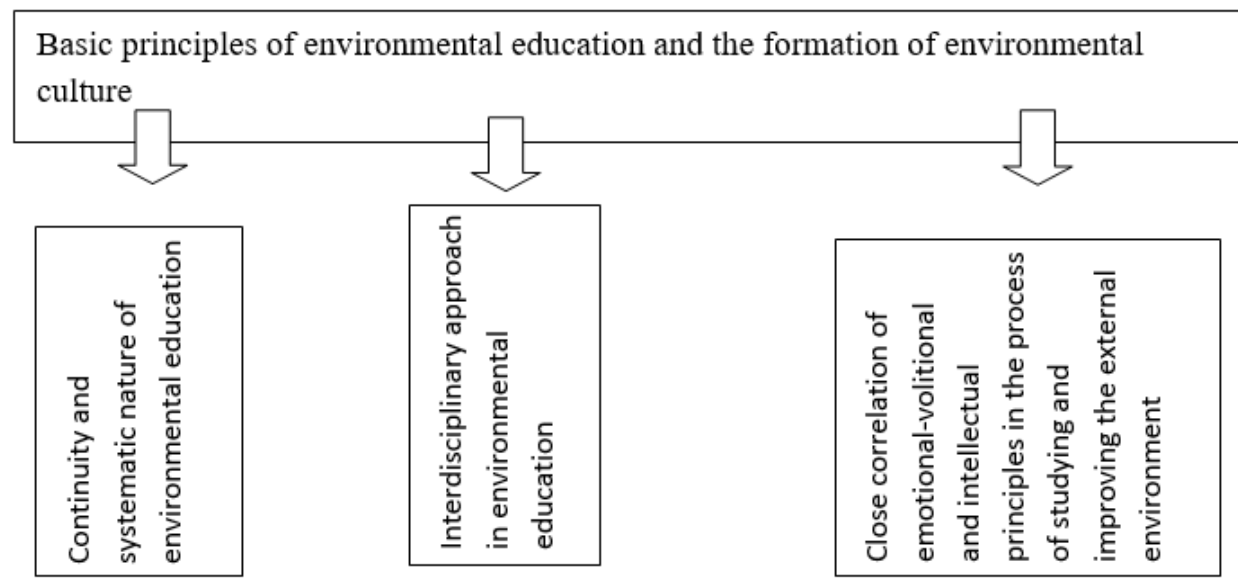

Fig. 2. Basic principles of environmental education and the formation of environmental culture

According to [12], the greatest effect in the direction of continuity and systematic environmental education can be achieved by taking into account the individual characteristics of students. The interdisciplinary approach makes it possible to define more clearly the significance of each academic discipline within the framework of the environmental education system.

This approach provides for mutual coordination of the content, forms and methods of environmental education.

According to [13], the correlation of emotional-volitional and intellectual principles determines the orientation of the learning process on the relationship of knowledge about the environment and its sensory and aesthetic perception.

According to [14], the formation of an ecological culture in a person allows him to realize the negative impact of human activity on the environment.

\section{Methods}

In the process of implementing this research work, the authors used an analytical method, which allowed us to consider the problems studied in the article in their development and unity.

Taking into account the task and purpose of the study, we used the functional-structural method of scientific cognition.

As a result the authors were able to study some problems related to the importance of environmental education for effective environmental management.

\section{Results}

The reason for writing this scientific work was the appeal to us of the management of a large machine-building enterprise in the city of Kharkiv. Technological processes at the enterprise have a negative impact on the environmental situation of the city. When the fines for pollution were low, the company did not pay due attention to environmental problems, believing that the cost of upgrading treatment facilities is too expensive and from an economic point of view it is more profitable to pay periodic fines. The employees of the enterprise, taking into account the lack of interest in environmental measures from the management, also treated this negligently. Employees believed that additional work 
responsibilities related to solving environmental problems are work that reduces labor productivity, which means that to perform it is to lose working time, and therefore lose part of the salary.

When the management of a machine-building enterprise decided to introduce environmental management in order to reduce fines for environmental pollution, it did not have much effect.

Before starting the study, we interviewed the employees with the knowledge of the company's management. We asked two questions.

1. How do you assess the environmental measures that the company's management is trying to implement?

2. Who should deal with the problem of environmental protection in the city of Kharkiv specialized environmental protection measures or all residents of the city?

The results of the survey were as follows: $68 \%$ of employees considered the new environmental measures as additional work, the performance of which will not be paid by the employer. $74 \%$ of employees believed that environmental problems should be dealt with by specialized environmental organizations, and not all residents of the city.

We suggested that the company's management conduct a webinar for the company's employees on the problem of environmental pollution in the city of Kharkiv and explain during the webinar how important the environmental measures proposed by the company's management are for the ecology of the city.

During the webinar, the employees listened to the report of the representative of the city environmental organization, and also discussed it at the webinar.

After the webinar, we re-interviewed the company's employees. The results showed that $46 \%$ considered new environmental measures as additional work, the implementation of which will not be paid , 53\% of employees believed that environmental problems should be dealt with by specialized environmental organizations, and not all residents of the city.

Thus, increasing the environmental education of the company's employees allows them to increase their interest in the successful functioning of the company's environmental management.

And therefore it increases the efficiency of environmental management in the enterprise.

\section{Discussion}

The need for environmental management is driven by the need to manage activities that cause or potentially cause harm to the environment.

The use of environmental management helps to reduce the burden on the natural environment from human economic activity

Environmental management allows us to harmonize the relationship between man and nature.

At the same time, the effectiveness of environmental management depends on how much people themselves are interested in protecting the environment and whether they have an environmental mindset.

Environmental management will be more effective if people are aware of the internal links between production processes and their impact on the environment.

The possibility of preserving the natural environment is possible only if a person takes a responsible attitude to this problem.

Human activity should be based on the awareness of the unity and interdependence of man and the natural environment. 


\section{Conclusions}

Environmental management helps to find a compromise between the interests of enterprises and the need for careful attitude to the environment.

Environmental management allows us to harmonize the relations of the natural environment and man.

The effectiveness of the functioning of environmental management increases if people have an understanding of the environment as a human habitat as a biological species and a responsible attitude to nature and its careful use.

\section{References}

1. Basharat Bhat, Suhaib Bandh, Environmental Management (2021)

2. Odysseas Kopsidas, Environmental Management and Technology (2021)

3. M.G. Hart, Environmental management (2020)

4. W. Yates, Environmental Management (2020)

5. Asit Bhattacharyya, Kumar Biswas, Australian Journal of Environmental Education (2020)

6. Reshmi Das, Meenakshi Mukherjee, Earth Science in Environmental Management (2021)

7. B. Nagla, Ecology, Culture and Development (2021)

8. Sergey Yekimov, Yevhenii Karmanny, Andrii Zenin, Iliana Zinovatna and Serhii Sliusarenko (2021) Using the project method to improve environmental education for law students E3S Web of Conferences 265, 07005.

9. Vusale Hajiyeva, PIRETC-Proceeding of The International Research Education \& Training Centre, 11, 11-16, (2021)

10. Ye. Sanzhieva, V. Radnaeva, East-Siberian State Institute of Culture (VSGIK), 172, 63 (2020)

11. Natalya Melnik, Ecological Culture: Extra-Evaluative Interpretation, 608 (2020)

12. M.I. Yaroslavtseva, S.V. Kolosova, Yu.V. Syrova, Innovate Pedagogy, 2, 144 (2021)

13. Davis Vallesi, Canadian Journal of Communication, 45 (2020)

14. Sergey Yekimov, Vitalii Vasylyshyn, Valentina Tsyna, Andriy Tsyna and Valentina Tytarenko (2021) Using the project method to motivate students studying physics J. Phys.: Conf. Ser. 1889, 022016. 